\title{
Organotellurium ligands - designing and complexation reactions
}

\author{
AJAI K SINGH \\ Department of Chemistry, Indian Institute of Technology, \\ New Delhi 110 016, India \\ e-mail: aksingh@chemistry.iitd.ernet.in
}

\begin{abstract}
A variety of tellurium ligands has been designed and studied for their complexation reactions in the last decade. Of these hybrid telluroethers, halotellurium ligands and polytellurides are the most notable ones. $\mathrm{RTe}^{-}$and polytelluride ions have also been used to design clusters. Ligation of ditelluroethers and several hybrid telluroethers is extensively studied in our laboratories. The ditelluroether ligand $\mathrm{RTeCH}_{2} \mathrm{TeR}$ (where $\mathrm{R}=4-\mathrm{MeOC}_{6} \mathrm{H}_{4}$ ) (1), similar to dppm [1,2-bis(diphenylphosphino)methane], has been synthesized in good yield ( $\sim 80 \%)$ by reacting $\mathrm{CHCl}_{3}$ with $\mathrm{RTe}^{-}$(generated in situ by borohydride reduction of $\mathrm{R}_{2} \mathrm{Te}_{2}$ ). Iodine reacts with 1 to give tetra-iodo derivative, which has intermolecular Te...I interactions resulting in a macro structure containing rectangular Te-I $\cdots$ Te bridges. 1 readily forms four membered rings with $\mathrm{Pd}(\mathrm{II})$ and $\mathrm{Ru}(\mathrm{II})$. On the formation of this chelate ring, the signal in ${ }^{125} \mathrm{Te}$ NMR spectra shifts significantly upfield $(50-60 \mathrm{ppm})$. The bridging mode of 1 has been shown in $\left[\mathrm{Ru}(p\right.$-cymene $\left.) \mathrm{Cl}_{2}\right](\mu-\mathbf{1})\left[\mathrm{Ru}(p\right.$-cymene $\left.) \mathrm{Cl}_{2}\right]$. The hybrid telluroether ligands explored are of the types $\left(\mathrm{Te}_{x}, \mathrm{~S}_{y}\right),\left(\mathrm{Te}_{x}, \mathrm{~N}_{y}\right)$ and $\left(\mathrm{Te}_{x}, \mathrm{O}_{y}\right)$. The tellurium donor site has strong trans influence, which is manifested more strongly in square planar complexes of palladium(II). The morpholine $\mathrm{N}$-donor site has been found to have weaker donor characteristics in $\left(\mathrm{Te}_{x}, \mathrm{~N}_{y}\right)$ ligands than pyridine and alkylamine donor sites of analogous ligands. The singlet oxygen readily oxidises the coordinated Te. This oxidation follows first order kinetics. The complexation reaction of $\mathrm{RuCl}_{3} . x \mathrm{H}_{2} \mathrm{O}$ with $\mathrm{N}$-[2-(4-methoxyphenyltelluro)ethyl]phthalimide (2) results in a novel (Te, N, O)-heterocycle, Te-chloro,Te-anisyl-1a-aza-4-oxa-3-tellura-1H, $2 \mathrm{H}$, 4aH-9 fluorenone. The (Te, O) ligands can be used as hemilabile ligands, the oxygen atom temporarily protects the vacant coordination site before the arrival of the substrate. The chelate shifts observed in ${ }^{125} \mathrm{Te}$ NMR spectra of metal complexes of Te-ligands have a close parallel to those of ${ }^{31} \mathrm{P}$ NMR. For the formation of fivemembered rings, the value is positive and of the order of $130 \mathrm{ppm}$ whereas for sixmembered rings it is negative and $\sim 30 \mathrm{ppm}$ only.
\end{abstract}

Keywords. Organotellurium ligands; hybrid telluroether; platinum metal complexes; tellurium-125 NMR.

\section{Introduction}

Tellurium is the noblest metalloid which may act as a Lewis acid as well as Lewis base. The ligand chemistry of tellurium, which acts as a 'soft' donor, was little explored before 1970 , probably due to commercial non-availability of a wide variety of tellurium/ organotellurium ligands and some misconception that they are air-sensitive, foul-smelling and toxic. In last three decades, a good number of publications devoted to them has appeared in the literature. This evidences considerable and continuous increase in the interest in tellurium ligands ${ }^{1,2}$. However, even today not many tellurium ligands are available commercially. With modern FT-NMR instruments there is a good possibility of 
using ${ }^{125}$ Te NMR to understand the solution behaviour of the metal-tellurium bond containing systems. This coupled with the fact that metal complexes of organotellurium ligands ${ }^{3}$ may be used as single source precursors for MOCVD of II-VI semiconductors, has enhanced interest in ligand chemistry of tellurium. Apart from organotellurium ligands there is also a current interest in inorganic tellurium ligands viz. halogenotellurium donors, telluride and polytelluride ligands. Ligand chemistry of polytelluride ions has been reviewed few years ago ${ }^{4}$. The chemistry of inorganic halogenotellurium ligands, e.g. $\mathrm{TeX}_{3}{ }^{-}$has been compiled by Beck ${ }^{5}$ and of tellurometalates $\left[\mathrm{M}_{\mathrm{x}} \mathrm{Te} \mathrm{y}^{2-}\right.$ by Ansari et $a l^{6}$.

In last one and a half decade, nearly three dozen polydentate telluroether ligands including ditelluroether and hybrid telluroethers) have been synthesized in our laboratory. In this report we briefly discuss our recent work on the ligand chemistry of ditelluroether ligand $\mathrm{RTeCH}_{2} \mathrm{TeR}$ (where $\mathrm{R}=4-\mathrm{MeOC}_{6} \mathrm{H}_{4}$ ) (1), which is similar to dppm [1,2bis(diphenylphosphino)methane] the $\left(\mathrm{Te}_{x}, \mathrm{~N}_{y}\right)$ type hybrid organotellurium ligands viz. N-[2-(4-methoxyphenyltelluro)ethyl]phthalimide (2) and N-\{2-(4-methoxyphenyltelluro)-ethyl $\}$ morpholine (3) and bis $\{2$-(N-morpholino)ethyl $\}$ telluride (4), $\left(\mathrm{Te}_{x}, \mathrm{O}_{y}\right)$ type ligands viz. 2-(4-ethoxyphenlytelluromethyl)tetrahydro-2H-pyran (5), 2-(2-\{4-ethoxyphenyl $\}$-telluroethyl)-1,3-dioxane (6), bis(2-\{1,3-dioxan-2-yl $\}$ ethyl) telluride(7) and (Te, S) type ligand 1-(4-methoxyphenylelluro)ethyl ethyl sulphide (8).

\section{Results and discussion}

\subsection{Ditelluroethers}

For the tellurium analogue of dppm, $\mathrm{RTeCH}_{2} \mathrm{TeR}(\mathbf{1})$, where $\mathrm{R}=\mathrm{C}_{6} \mathrm{H}_{5}$, 4- $\mathrm{MeOC}_{6} \mathrm{H}_{4}$ a very clean and high yield $(\sim 80 \%)$ synthesis based on the reaction of $\mathrm{CHCl}_{3}$ with $\mathrm{ArTe}^{-}$(generated in situ in ethanol by $\mathrm{NaBH}_{4}$ reduction of $\mathrm{Ar}_{2} \mathrm{Te}_{2}$ ) has been reported recently ${ }^{7}$. The first structurally characterized complexes ${ }^{8}$ of a chelating $\mathrm{C}_{1}$ linked ditelluroether 1 are $\left[\left\{\right.\right.$ meso $\left.\left.\left(4-\mathrm{MeOC}_{6} \mathrm{H}_{4} \mathrm{Te}\right)_{2} \mathrm{CH}_{2}\right\}(\mathrm{dppe}) \mathrm{Pd}(\mathrm{II})\right]\left(\mathrm{ClO}_{4}\right)_{2} \cdot 4 \mathrm{H}_{2} \mathrm{O}$ (9) and [meso(4- $\left.\left.\left.\mathrm{MeOC}_{6} \mathrm{H}_{4} \mathrm{Te}\right)_{2} \mathrm{CH}_{2}\right\} \mathrm{Pd}(\mathrm{II}) \mathrm{Cl}_{2}\right] \quad$ (10) (dppe = [1,2-bis(diphenylphosphino)ethane]). The synthesis of $\mathbf{9}$ and $\mathbf{1 0}$ is contrary to the claim of Chiffey et al ${ }^{9}$, that $\mathbf{1}$ always make polymeric complexes with $\mathrm{Pd}(\mathrm{II})$. The solubility of $\mathbf{9}$ in common organic solvents is of course very poor. The ${ }^{125} \mathrm{Te}\left\{{ }^{1} \mathrm{H}\right\}$ NMR spectrum of $\mathbf{9}$ has only one prominent signal at $\boldsymbol{\delta}$ 509 (signal of free $1 ; \delta 571 \mathrm{ppm}$ ) favouring the presence of meso invertomer.

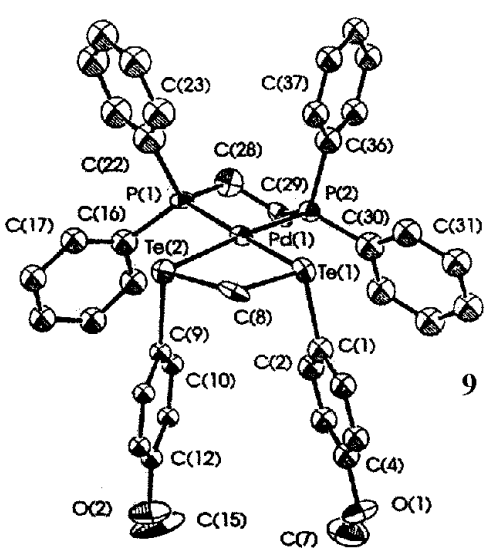


The oxidative addition of iodine with $\mathbf{1}$ results in $\left\{4-\mathrm{MeO}-\mathrm{C}_{6} \mathrm{H}_{4} \mathrm{Te}\left(\mathrm{I}_{2}\right)\right\}_{2} \mathrm{CH}_{2}$. The crystal structure of $\mathbf{1}$ and $\left\{4-\mathrm{MeO}-\mathrm{C}_{6} \mathrm{H}_{4} \mathrm{Te}\left(\mathrm{I}_{2}\right)\right\}_{2} \mathrm{CH}_{2}$ (1a) have been reported ${ }^{10}$. The $\mathrm{Te}(1)-\mathrm{C}(1)-\mathrm{Te}(2)$ bond angle $\left(117 \cdot 0(2)^{\circ}\right)$ in $\mathbf{1}$ is larger than the expected value of about $109^{\circ}$, probably due to the steric influence of the two ArTe groups. However it is consistent with there being little or no Te-C $\pi$-bonding in the aliphatic link. The bite of $\mathbf{1}$ is greater than that of dppm [1,2-bis(diphenylphosphino)methane] due to the larger size of tellurium. The environment of both tellurium atoms in 1a is that of the typical sawhorse structure associated with $\mathrm{Te}(\mathrm{IV})$ compounds. The two iodine atoms occupy axial positions with angles close to $180^{\circ}$. Two of the Te-I bonds, $\mathrm{Te}(1)-\mathrm{I}(2)$ and $\mathrm{Te}(2)-\mathrm{I}(4)$, are longer (average 3.063(3) $\AA$ ) than the other two, Te(1)-I(1) and Te(2)-I(3) (average $2 \cdot 815(8) \AA)$. I(2) and $I(4)$ have intermolecular contacts with their neighbouring Te atoms at distances (3.735(1) and 3.879(1) $\AA$ ) considerably less than the sum of their van der Waal's radii of $4.35 \AA$. These interactions apparently lead to polymeric links of essentially $\mathrm{Te}-\mathrm{I}-\mathrm{Te}^{\prime}-\mathrm{I}^{\prime}$ rectangular bridges (angles $89.07(3)$ to $\left.94 \cdot 68(3)^{\circ}\right)$. The carbon atom of the methoxyphenyl group attached to tellurium and that of methylene occupy two of the equatorial positions, with the supposed lone pair occupying the third. Despite the presence of the four iodine atoms, the $\mathrm{Te}(1)-\mathrm{C}(8)-\mathrm{Te}(2)$ bond angle $115.5(6)^{\circ}$ is very close to that of the corresponding angle of $\mathbf{1}$, i.e. 117.0(2) .

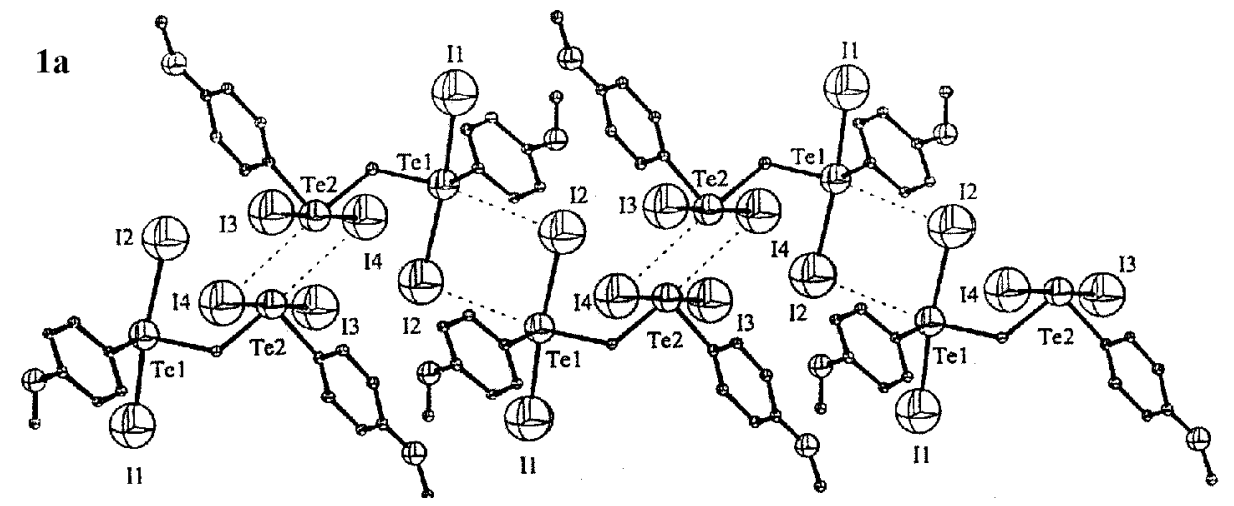

The complex cis-[Ru(DMSO $\left.)_{2}(\mathrm{Cl})_{2}(\mathbf{1})\right]$ (11) is formed by substitution of two DMSO molecules in cis-[Ru(DMSO $\left.)_{4} \mathrm{Cl}_{2}\right]$ with $\mathbf{1}$. The complex $\mathbf{1 1}$ is the first example of a ruthenium-ditelluroether complex ${ }^{10}$ for which single crystal structure has been solved. The geometry of ruthenium in $\mathbf{1 1}$ is distorted octahedral. The bond lengths $\mathrm{Ru}(1)-\mathrm{Te}(1)$ $(2.599(5) \AA)$ and $\mathrm{Ru}(1)-\mathrm{S}(2)(2.244(1) \AA)$, in which tellurium and sulphur atoms are trans to $\mathrm{Cl}$, are both shorter than the corresponding $\mathrm{Ru}(1)-\mathrm{Te}(2)(2 \cdot 673(5) \AA)$ and $\mathrm{Ru}(1)-\mathrm{S}(1)(2 \cdot 314(1) \AA)$ bond lengths, where the Te and $\mathrm{S}$ atoms are trans to each other. Both the $\mathrm{Ru}-\mathrm{Cl}$ bond lengths are essentially identical with one $\mathrm{Cl}$ atom being trans to $\mathrm{Te}$ atom and the other trans to an $\mathrm{S}$ atom. The $\mathrm{Te}(1)-\mathrm{Ru}(1)-\mathrm{Te}(2)$ bite angle is $78.2(2)^{\circ}$, which can be compared to the values of $82.0(3)$ and $79.6(3)^{\circ}$ for Te-Pd-Te angles in the complexes 9 and 10. However in the complex 11 the ditelluroether ligand is not in meso form. The distortions from all $90^{\circ}$ angles in the octahedron about ruthenium are apparently not equally shared between the two tellurium atoms. The angles involving $\mathrm{Te}(1)$ display much larger distortions of cis angles, $76 \cdot 6(2)^{\circ}$ for $\mathrm{Te}(1)-\mathrm{Ru}(1)-\mathrm{Cl}(2)$ to 99.6(3) ${ }^{\circ}$ for $\mathrm{Te}(1)-\mathrm{Ru}(1)-\mathrm{S}(2)$ than those involving $\mathrm{Te}(2)$, 87.0(3) ${ }^{\circ}$ for $\mathrm{Te}(2)-\mathrm{Ru}(1)-$ $\mathrm{Cl}(2)$ to $93.5(3)^{\circ}$ for $\mathrm{Te}(2)-\mathrm{Ru}(1)-\mathrm{Cl}(1)$. Further the 'plane' not involving $\mathrm{Te}(1)$, which 
contains the five atoms, $\mathrm{Te}(2), \mathrm{Ru}(1), \mathrm{S}(1), \mathrm{S}(2)$ and $\mathrm{Cl}(2)$ is planar within $0.008 \AA$ while the one that includes $\mathrm{Te}(1)$ shows greater distortion from planarity, with $\mathrm{Te}(1), \mathrm{Te}(2)$, $\mathrm{Ru}(1), \mathrm{S}(1)$ and $\mathrm{Cl}(1)$ at $0.05 \AA$ and $\mathrm{Te}(1), \mathrm{Ru}(1), \mathrm{S}(2), \mathrm{Cl}(1)$ and $\mathrm{Cl}(2)$ at $0.07 \AA$. The $\mathrm{Te}-\mathrm{C}$ (aromatic) distances, $2 \cdot 120(5)$ and $2 \cdot 124(5) \AA$ are clearly shorter than those of Te-C(aliphatic) $(2 \cdot 145(5)$ and $2 \cdot 146(5) \AA)$, a general phenomenon reported earlier also ${ }^{2}$. However this is in contrast to free ligand in which all the $\mathrm{Te}-\mathrm{C}$ bonds are essentially identical and also in contrast to what was observed for the two complexes of $\mathrm{Pd}(\mathrm{II})$ with 1, but the bond lengths in these structures were less well-resolved. The value of $\mathrm{Te}-\mathrm{C}-\mathrm{Te}$ bond angle, 101.6(2) $)^{\circ}$ in $\mathbf{1 1}$ concurs with no or little Te-C $\pi$-bonding, but it is lower than those observed for Pd(II) complexes of $\mathbf{1}$. The average $\mathrm{C}-\mathrm{Te}-\mathrm{C}$ angle $97 \cdot 4^{\circ}$ in $\mathbf{1 1}$ does not vary significantly from that of free $\mathbf{1}\left(98 \cdot 1^{\circ}\right)$. In the ${ }^{1} \mathrm{H}$ and ${ }^{13} \mathrm{C}$ NMR spectra of $\mathbf{1 1}$, the $\mathrm{CH}_{2}$ signals undergo deshielding $(0.08$ and $30 \mathrm{ppm}$ respectively) consistent with its structure. In the ${ }^{1} \mathrm{H}$ NMR spectrum of crystals of $\mathbf{1 1}$ signals multiply after one hour of dissolution, indicating the formation of other trans isomers of 11, complex species containing O-bonded DMSO (signal at $\delta 2.90 \mathrm{ppm}$ ) and the presence of free DMSO (signal at $\delta$ 2.61 ppm). The complex $\left[\left(\mathrm{Ru}(p\right.\right.$-cymene $\left.\left.) \mathrm{Cl}_{2}\right) .1\right]$ (11a) is also structurally characterized and has ligand $\mathbf{1}$ bonded in a bridging mode ${ }^{10}$.

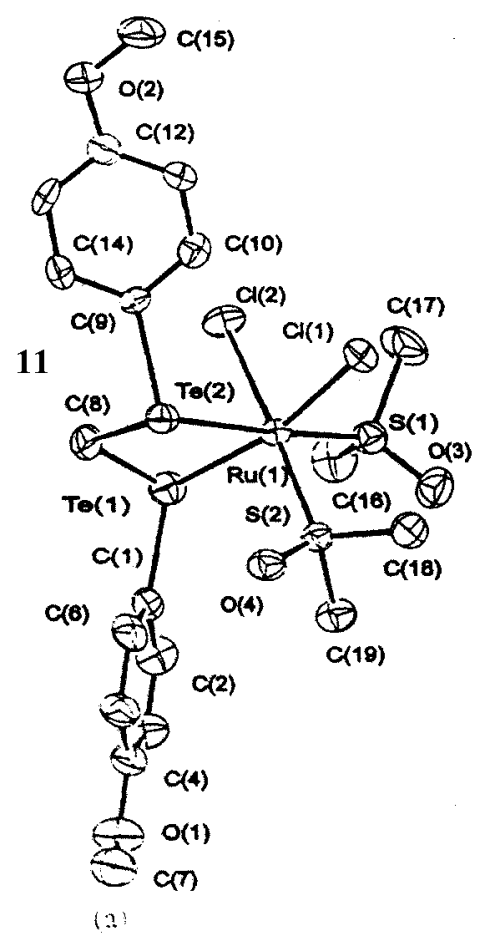

\subsection{Hybrid telluroethers}

In the last two decades, a few dozens of a variety of hybrid telluroether ligands have been explored for their ligation behaviour. Of these, a good number have been investigated in our research laboratory. Some very recent results are presented here. The common strategies used to design such ligands are the reactions of appropriate organic halides with $\mathrm{ArTeNa}, \mathrm{ArTeLi}$ or $\mathrm{Na}_{2} \mathrm{Te}$. N-[2-(4-methoxyphenyltelluro)ethyl]phthalimide (2) 


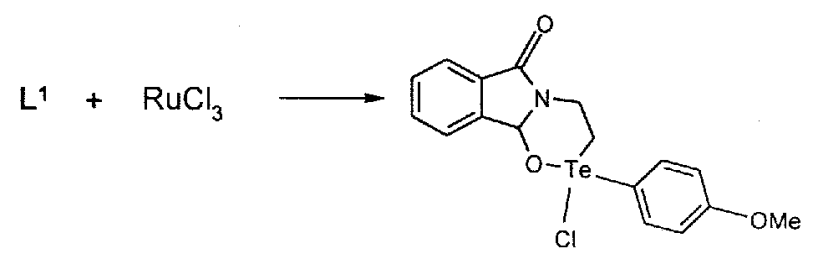

reacts with $\mathrm{RuCl}_{3} \cdot \mathrm{H}_{2} \mathrm{O}$ resulting in a novel heterocycle as shown in (1). The heterocycle Te-chloro, Te-anisyl-1a-aza-4-oxa-3-tellura-1H, 2H, 4aH-9-fluorenone (12) is characterized structurally ${ }^{11}$. In the formation of 12 Te is oxidized to the + IV oxidation state as its electron pair geometry is typically that of a Te(IV) species, conforming to a trigonal bipyramidal arrangement by placing a lone pair at one corner of the trigonal plane. The oxygen and chlorine atoms are trans to each other. The $\mathrm{C}(1)-\mathrm{Te}-\mathrm{C}(8)$ angle $\left(109 \cdot 0(2)^{\circ}\right)$ in 12 is a little higher than that of $2\left(97.4(2)^{\circ}\right)$. The Te-C bond lengths are also somewhat shortened on the formation of 12. So far no tellurium heterocycle containing three heteroatoms is known and $\mathbf{1 2}$ is the first such example. Moreover, in the ${ }^{13} \mathrm{C}$ NMR spectrum of 12, the signal due to $\mathrm{TeCH}_{2}$ shows $\sim 50 \mathrm{ppm}$ downfield shift with respect to that of free 2, concurring well with the formation of the Te(IV) species. The half sandwich compound [ $(p$-cymene $\left.) \mathrm{RuCl}_{2} \cdot 2\right]$ is also characterized structurally. In this half sandwich compound, $p$-cymene is in a $\eta^{6}$ bonding mode (Ru-C(av.) 2.192(1) $\AA$ ) and $\mathrm{Te}-\mathrm{C}(\mathrm{alkyl})$ has been found to be longer than Te-C(aryl).

$\mathrm{N}$-\{2-(4-methoxyphenyltelluro)-ethyl $\}$ morpholine (3) and bis $\{2-(\mathrm{N}$-morpholino) ethyl -telluride $(\mathbf{4})$ are potentially $(\mathrm{Te}, \mathrm{N})$ and $\left(\mathrm{Te}, \mathrm{N}_{2}\right)$ type of ligands. Compound $\mathbf{4}$ is unstable but reaction of its freshly prepared sample with $\mathrm{Pd}(\mathrm{II})$ and $\mathrm{Hg}$ (II) in a $1: 2$ (metal:ligand) ratio stabilizes it. In the mass spectrum of $\mathbf{3}$ the molecular ion peak appears at $m / z, 351 . \mathrm{CH}_{2} \mathrm{~N}$ and $\mathrm{CH}_{2} \mathrm{Te}$ signals in the ${ }^{1} \mathrm{H}$ NMR spectrum of 4 merge together, as supported by its HETCOR spectrum. The reactions of $\mathbf{3}$ and $\mathbf{4}$ with palladium(II) in a 1:1 molar ratio have resulted in insoluble materials which defy all attempts at characterization, probably due to their polymeric nature. The complexes of stoichiometry $\left[\mathrm{Pd} / \mathrm{PtCl}_{2} \quad(\mathbf{3} / \mathbf{4})_{2}\right]$ are characterized structurally ${ }^{12,13}$. There are many similarities in the structures of complexes of $\mathbf{3}$ and $\mathbf{4}$. Both of them are trans square planar coordination compounds of the type $\left[\mathrm{PdCl}_{2}\left(\mathrm{RTeR}^{\prime}\right)_{2}\right]\left(\mathrm{R}=\mathrm{R}^{\prime}\right.$ for 3$)$. There is no exact symmetry in either of them, however in the latter, the coordination plane is a pseudo mirror plane and there is a pseudo centre of symmetry at palladium position. The tellurium atoms in both the complexes have distorted pyramidal molecular geometry, the electron pair geometry of which may be described as distorted tetrahedral, if a lone pair presumably occupies one corner. The lone pairs on two Te atoms of these complexes have a trans orientation with respect to the linear Te-Pd-Te system. The organic groups present on the two tellurium atoms in each complex are in an orientation of least steric interaction. In the complex of 3 the two $4-\mathrm{MeOC}_{6} \mathrm{H}_{5}$ groups present on different $\mathrm{Te}$ atoms are also trans to the Te-Pd-Te system.

The average values of $\mathrm{Pd}(\mathrm{II})-\mathrm{Te}$ bond lengths in the complexes of $\mathbf{3}$ and $\mathbf{4}$ are very similar (2.596 and $2.600 \AA$, respectively). The sum of covalent radii of square planar $\operatorname{Pd}$ (II) $(1.31 \AA)$ and pyramidal Te(II) $(1.32 \AA)$ is $2.63 \AA$ and comparable with the present averages. The $\mathrm{Pd}-\mathrm{Te}$ bonds in these complexes are longer in comparison to those which are trans to $\mathrm{Pd}-\mathrm{Cl}^{7,8}$. Thus the trans influence of Te has a very significant effect on the $\mathrm{Pd}-\mathrm{Te}$ bond lengths of a trans Te-Pd-Te system. 

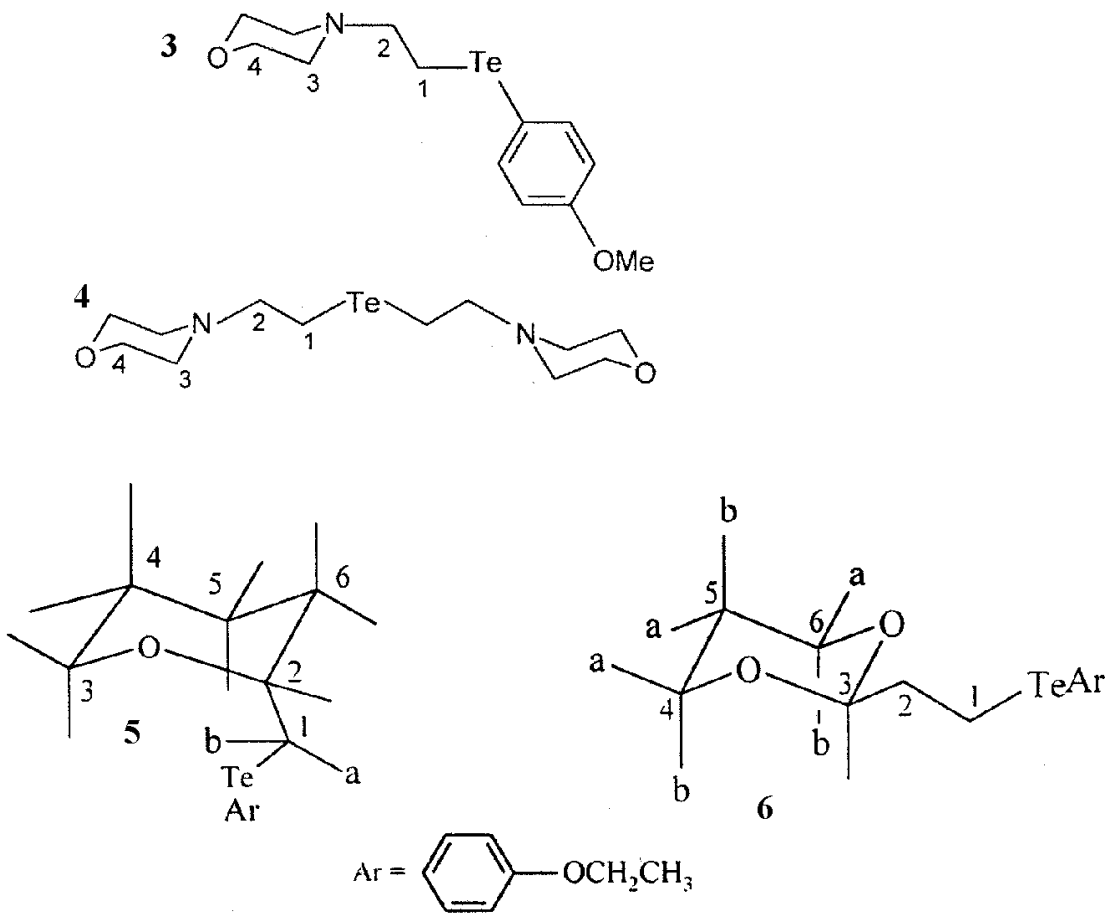

2-(4-Ethoxyphenlytelluromethyl)tetrahydro-2H-pyran (5), 2-(2-\{4-ethoxyphenyl $\}$ telluroethyl)-1,3-dioxane (6), and bis(2-\{1,3-dioxan-2-yl\}ethyl) telluride(7) are hemilabile organotellurium ligands investigated in the recent past ${ }^{14,15}$.

In the proton NMR spectrum of $\mathbf{5}$, the $\mathrm{H}_{4}, \mathrm{H}_{5}$ and $\mathrm{H}_{6}$ protons merge together and appear as a multiplet in the region of $1.24-1.96 \mathrm{ppm}$. The $\mathrm{H}_{1}$ protons are not magnetically equivalent. The $\mathrm{H}_{1 \mathrm{a}}, \mathrm{H}_{1 \mathrm{~b}}$ and $\mathrm{H}_{2}$ protons constitute an AA'B type spin system. Thus $\mathrm{H}_{1 \mathrm{a}}$ and $\mathrm{H}_{1 \mathrm{~b}}$ protons appear as two multiplets of equal intensity in the regions 2.87-2.91 and 3.04-3.08 ppm respectively. The magnetic non-equivalence of $\mathrm{H}_{1 \mathrm{a}}$ and $\mathrm{H}_{1 \mathrm{~b}}$ protons is supported by the HETCOR spectrum of $\mathbf{5}$, in which both $\mathrm{H}_{1 \mathrm{a}}$ and $\mathrm{H}_{1 \mathrm{~b}}$ appear as multiplets but have only one ${ }^{13} \mathrm{C}\left\{{ }^{1} \mathrm{H}\right\}$ cross peak. The diiodo derivative $\left[\mathbf{5}(\mathrm{I})_{2}\right]$ is formed through oxidative addition of iodine to tellurium of 5. The ${ }^{1} \mathrm{H}$ NMR spectrum of this diiodo derivative is characteristic. The $\mathrm{H}_{1 \mathrm{a}}$ and $\mathrm{H}_{1 \mathrm{~b}}$ signals, are deshielded ( 0.6-0.8 ppm) with respect to those of free $\mathbf{5}$. This concurs with the +IV oxidation state of its tellurium. The half sandwich $\mathrm{Ru}$ complexes of $\mathbf{5}$ and $\mathbf{6}$ in which the coordination sphere of metal is composed of two chloride ligands, $\eta^{6}$-bonded $p$-cymene ring and ligand $\mathbf{5 / 6}$ coordinated through Te are characterized structurally. The Ru-Te bond length (2.6197(8) $\AA$ ) in the complex of $\mathbf{5}$ is consistent with the literature value 2.619(4)-2.650(1) $\AA$ reported for $\left[\mathrm{Ru}\left\{\mathrm{PhTe}\left(\mathrm{CH}_{2}\right)_{3} \mathrm{TePh}\right\}_{2} \mathrm{Cl}_{2}\right]$ and $\left[\mathrm{Ru}\left\{\mathrm{MeTe}\left(\mathrm{CH}_{2}\right)_{3} \mathrm{TeMe}\right\}_{2} \mathrm{ClPPh}_{3}\right] \mathrm{PF}_{6}{ }^{16}$. The average value for $\mathrm{Ru}-\mathrm{C}$ bond length is $2 \cdot 189 \AA$ and concurs with the values reported for $11 a^{10}$. The pyran ring has chair conformation as expected. The $\mathrm{Ru}-\mathrm{Cl}$ bond distances $2 \cdot 4205(12)$ and $2 \cdot 4136(12) \AA$ are normal and consistent with the literature values $2 \cdot 4173(8) \AA^{17}$, reported for $\left[\mathrm{RuCl}\left\{\eta^{2}-\mathrm{C}, \mathrm{N}-\mathrm{C}_{6} \mathrm{H}_{3}\left(\mathrm{CH}_{2} \mathrm{NMe}_{2}\right)_{2}-2,6\right\}\left\{\eta^{6}-\mathrm{C}_{10} \mathrm{H}_{14}\right\}\right]$. The aromatic ring of $p$-cymene ligand is almost planar $(\mathrm{C}-\mathrm{C}-\mathrm{C}$ bond angles vary from $116 \cdot 8(3)$ to $\left.122 \cdot 3(4)^{\circ}\right)$ and is perpendicular to $\mathrm{Ru}$. The $\mathrm{Ru}-\mathrm{Te}$ bond length in the complex of $\mathbf{6}$ is $2.642(1) \AA$ and consistent with that of a similar complex of $\mathbf{5}$. The dioxane ring 
has chair conformation as expected. The $\mathrm{Ru}-\mathrm{Cl}$ bond distances in the complex of 6 $(2 \cdot 404(3)$ and $2 \cdot 415(3) \AA)$ are normal. The potentially $\left(\mathrm{Te}, \mathrm{O}_{2}\right)$ type of ligand 7 is stabilized on the formation of complexes $\left[\mathrm{Ru}(p\right.$-cymene $\left.) \mathrm{Cl}_{2} .7\right](\mathbf{1 3})$ and trans- $\left[\mathrm{PdCl}_{2}(\mathbf{7})_{2}\right]$ (14) which are characterized structurally ${ }^{14}$. The $\mathrm{Ru}-\mathrm{Te}$ bond length in the half sandwich compound 13 is $2 \cdot 6559(9) \AA$ The geometry of Pd in $\mathbf{1 4}$ is square planar. The Pd-Te bond length in $\mathbf{1 4}$ is $2 \cdot 5873(2) \AA$ The $\mathbf{1 3}$ and $\mathbf{1 4}$ are the first examples of structurally
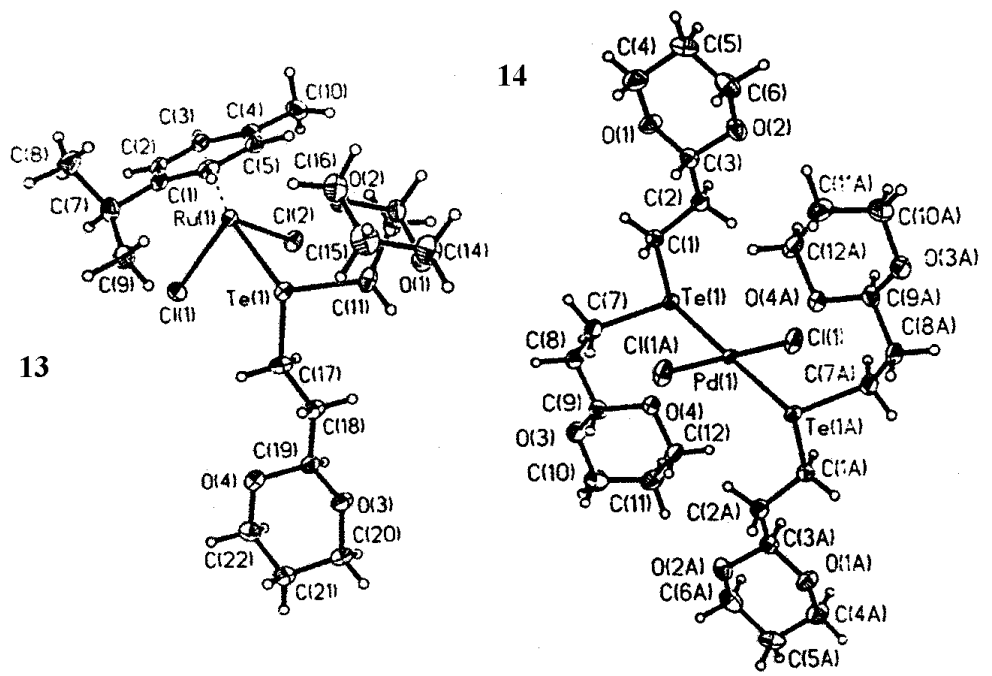

characterized complexes in which potentially $\left(\mathrm{Te}, \mathrm{O}_{2}\right)$ type ligand molecules are present, and coordinate through Te. The reactions of ruthenium(II) complexes of hemilabile ligands of $\left(\mathrm{Te}, \mathrm{O}_{x}\right)$ type $(x=1$ or 2$)$ with silver perchlorate result in species in which $\mathrm{Ru}$ is coordinated by ethereal oxygen. This $\mathrm{Ru}-\mathrm{O}$ bond is found to be labile and is cleaved for several substrates easily.

\subsection{Trans-influence of tellurium ligands}

The trans influence of telluroether donor sites has been presumed most of the time as some what lower or at the most, nearly equal to that of thioether one. We have recently observed $^{18}$ that $\mathrm{Pt}-\mathrm{Cl}$ trans to $\mathrm{SMe}$ is $2 \cdot 324(4) \AA$, whereas in the same molecule of complex, $\left[\mathrm{PtCl}_{2}\left(4-\mathrm{EtOC}_{6} \mathrm{H}_{4} \mathrm{TeCH}_{2} \mathrm{CH}_{2} \mathrm{SMe}\right)\right], \mathrm{Pt}-\mathrm{Cl}$ trans to ArTe is 2.336(3) $\AA$. This observation prompted us to synthesize a palladium complex of the same (Te, S) ligand and study further the more general status of relative trans influence of telluro and thioethers. As suitable crystals of palladium(II) complex of $4-\mathrm{EtOC}_{6} \mathrm{H}_{4} \mathrm{TeCH}_{2} \mathrm{CH}_{2} \mathrm{SMe}$ could not be grown, a similar ligand 8 having SEt and $4-\mathrm{MeOC}_{6} \mathrm{H}_{4}$ groups was synthesized. Its palladium complex, $\left[\mathrm{PdCl}_{2} .8\right]$ (15) gives crystals suitable for X-ray diffraction ${ }^{19}$. The geometry of donor atoms around palladium is slightly distorted square planar. The $\mathrm{Pd}-$ $\mathrm{Cl}(2)$ is trans to the ArTe group and longer by $0.028 \AA$ than $\mathrm{Pd}-\mathrm{Cl}(1)$ which is trans to SEt. This suggests that trans influence of ArTe is probably greater in comparison to that of the thioether donor group SEt. The stronger $\sigma$-donation ${ }^{16}$ characteristic of Te in comparison to that of S seems to be responsible for its greater trans influence. 
15

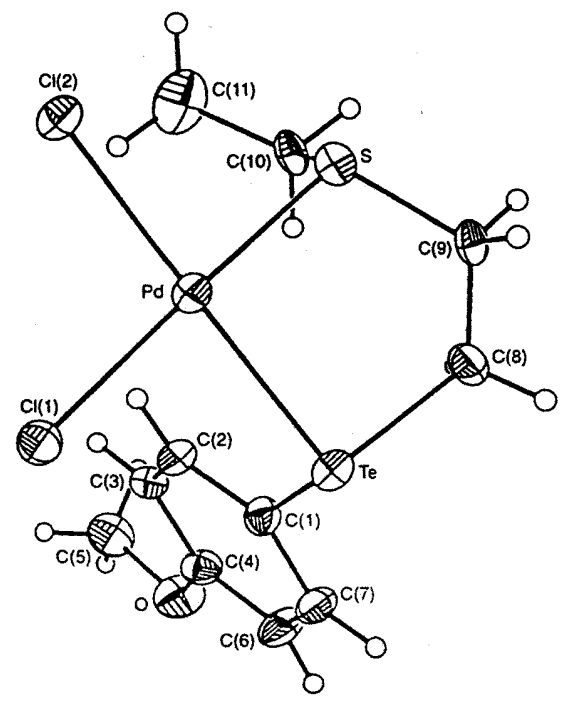

\section{$2.4 \quad{ }^{125}$ Te NMR spectra}

The ${ }^{125} \mathrm{Te} \mathrm{NMR}$ of ligands 6 and 7 and their complexes $\left[\mathrm{Pd} / \mathrm{PtCl}_{2}(\mathbf{6} / 7)_{2}\right]$ and $[\mathrm{Pd} / \mathrm{Pt}$ $\left.(6 / 7)_{2}\right]\left(\mathrm{ClO}_{4}\right)_{2}$ have been investigated the results are summarized in table 1 . The chelate parameter for five-membered rings is positive and large in comparison to six-membered rings for which it is negative and small. Parallel behaviour of chelate parameters is wellknown for ${ }^{31} \mathrm{P}$ NMR spectra.

\subsection{Reaction of complexes of Te-ligands with singlet oxygen}

The reaction of $\left[\mathrm{Pd}(\mathrm{phen})(\mathbf{5} / \mathbf{6})_{2}\right]\left(\mathrm{ClO}_{4}\right)_{2}$ with singlet oxygen has been followed in solution by monitoring the LLCT band of the complex at $450 / 452 \mathrm{~nm}$, which disappears with time indicating that the Te atom is oxidized by the singlet oxygen resulting in the decomposition of the complex. The plots of $\log [$ complex] vs time are linear.

Table 1. ${ }^{125}$ Te NMR data.

\begin{tabular}{|c|c|c|}
\hline Ligand/complex & Chemical shift $\delta(\mathrm{ppm})$ & Chelate parameter \\
\hline 5 & 489 & \\
\hline 6 & 467 & \\
\hline$\left[\mathrm{PdCl}_{2}(\mathbf{5})_{2}\right]$ & 642 & \\
\hline$\left[\mathrm{PdCl}_{2}(\mathbf{6})_{2}\right]$ & 626 & \\
\hline$\left[\mathrm{Pd}(\mathbf{5})_{2}\right]\left(\mathrm{ClO}_{4}\right)_{2}$ & 769 & +127 \\
\hline$\left[\mathrm{Pd} /(\mathbf{6})_{2}\right]\left(\mathrm{ClO}_{4}\right)_{2}$ & 607 & -19 \\
\hline$\left[\mathrm{PtCl}_{2}(\mathbf{5})_{2}\right]$ & 620 & \\
\hline$\left[\mathrm{PtCl}_{2}(\mathbf{6})_{2}\right]$ & 618 & \\
\hline$\left[\mathrm{Pt}(\mathbf{5})_{2}\right]\left(\mathrm{ClO}_{4}\right)_{2}$ & 732 & +112 \\
\hline$\left[\mathrm{Pt}(\mathbf{6})_{2}\right]\left(\mathrm{ClO}_{4}\right)_{2}$ & 602 & -16 \\
\hline
\end{tabular}




\section{Conclusion}

The reaction of chloroform with $\mathrm{ArTe}^{-}$gives a very pure sample of bis(aryltelluro) methane which chelates in a bidentate mode more easily than dppm due to its bigger bite. Its bridging mode of coodination is also established. The tetraiodo derivative of bis(aryltelluro)methane has an interesting structure as Te $\cdots$ I secondary interactions result in a macromolecular framework in the solid state. $\left[\mathrm{Ru}(\mathrm{DMSO})_{2} \mathrm{Cl}_{2}(\mathbf{1})\right]$ is the first example of a ruthenium-ditelluroether complex for which crystal structure has been solved. In this structure the geometry of $\mathrm{Ru}$ is distorted significantly indicating that if more than one molecule of $\mathbf{1}$ enters the coordination sphere of an octahedral complex, the probability of its acting in a chelating mode of coordination is much lower due to a limit on distortion tolerance and other steric reasons. The Te-chloro,Te-anisyl-1a-aza-4-oxa-3tellura-1H, 2H, 4aH-9-fluorenone (12), is a unique example of a tellura heterocycle containing oxygen as well as nitrogen in the same ring, formed by oxidation of $\mathbf{2}$ with $\mathrm{Ru}(\mathrm{III})$ unexpectedly. The first tellurated derivatives of morpholine, $\mathrm{N}-\{2$-(4-methoxyphenyltelluro) ethyl\}morpholine and bis 2 -(N-morpholino)ethyl $\}$ telluride are synthesized, which have a suitable bite for bi-/tri-dentate $(\mathrm{Te}, \mathrm{N}) /(\mathrm{N}, \mathrm{Te}, \mathrm{N})$ ligation. However, donor capability of morpholine nitrogen seems to be weaker in comparison to those of other nitrogen donors studied in conjunction with $\mathrm{Te}$ as both the ligands prefer to coordinate only through the Te. The trans influence of Te shows a very significant effect on the Pd-Te bond lengths. The trans influence of ArTe is shown to be stronger than that of SEt. The potentially (Te, O) ligands, 2-(4-ethoxyphenlytelluromethyl) tetrahydro- $2 \mathrm{H}$ pyran and 2-(2-\{4-ethoxyphenyl\}telluroethyl)-1,3-dioxane, which like (P,O) ligands exhibit hemilability and thus can be of some importance in the context of catalytically active species, have been authenticated structurally in $\left[\mathrm{RuCl}_{2}\right.$ (p-cymene).5/6]. The chelate parameter is found to behave in a manner similar to that of ${ }^{31} \mathrm{P}$ NMR. The Pd-Te bond is cleaved by singlet oxygen as Te is oxidized readily.

\section{Acknowledgements}

The author thanks the Department of Science \& Technology, New Delhi, India for financial support. He also thanks Drs J Sooriyakumar, M Misra, M Kadarkaraisamy, A Khalid, C V Amburose and R Batheja. The crystallographic support from Professors JE Drake (Canada), H Husebye (Norway) and R J Butcher (USA) is gratefully acknowledged.

\section{References}

1. Hope E G and Levason W 1993 Coord. Chem. Rev. 122109

2. Singh A K and Sharma S 2000 Coord. Chem. Rev. 20949

3. Singh H B and Sudha N 1996 Polyhedron 15745

4. Kanatzidis M G and Huang S P 1994 Coord. Chem. Rev. 130509

5. Beck J 1994 Angew. Chem. 106172

6. Ansari M, McConnachie J M and Ibers J A 1993 Acc. Chem. Res. 26574

7. Khalid A and Singh A K 1997 Polyhedron 1633

8. Drake J E, Yang J, Khalid A, Srivastava V and Singh A K 1997 Inorg. Chim. Acta 25457

9. Chiffey A F, Evans J, Levason W and Webster M 1994 J. Chem. Soc., Dalton Trans. 2835

10. Singh A K, Kadarkaraisamy M, Drake J E and Butcher R J 2000 Inorg. Chim. Acta 30445

11. Singh A K, Kadarkaraisamy M, Murthy G S, Srinivasa J, Varghese B and Butcher R J 2000 J. Organomet. Chem. $\mathbf{6 0 5} 39$ 
12. Singh A K, Sooriyakumar J, Husebye H and Tornroos K W 2000 J. Organomet. Chem. 61246

13. Singh A K, Sooriyakumar J and Butcher R J 2001 Inorg. Chim. Acta 312163

14. Singh A K, Sooriyakumar J, Drake J E, Hursthouse H B and Light M E 2000 J. Organomet. Chem. 613244

15. Singh A K, Kadarkaraisamy M, Mishra M, Sooriyakumar J, Drake J E, Hursthouse HB, Light M E and Jasinski J P 2001 Inorg. Chim. Acta 320133

16. Levason W, Orchard S D, Reid G and Tolhurst V A 1999 J. Chem. Soc., Dalton Trans. 2071

17. Steenwinkel P, James S L, Gossage R A, Grove D M, Kooijman H, Smeets W J J, Spek AL and van Koten G 1998 Organometallics 174680

18. Singh A K, Srivastava V, Dhingra, Drake J E and Bailey H E 1992 Acta Crystallogr. Sect C, 48655

19. Singh A K, Amburose C V, Misra M and Butcher R J 1999 J. Chem. Res (S) 716 